\title{
CONTENTS
}

Acknowledgments $\quad \mathrm{xi}$

Introduction: Public Controversies and Identity Politics in Writing Center Theory and Practice

Harry Denny, Robert Mundy, Liliana M. Naydan, Richard Sévère, and Anna Sicari 3

\section{PART I: RACE}

1 Being Seen and Not Seen: A Black Female Body in the Writing Center

Talisha Haltiwanger Morrison 21

2 A Touching Place: Womanist Approaches to the Center Alexandria Lockett 28

3 Black Male Bodies in the Center

Richard Sévère 43

4 Bodies in Space: His, Hers, and My Race Allia Abdullah-Matta 51

5 Sacred Pages: Writing as a Discursive Political Act

Rochell Isaac 66

Part I: Review 75

\section{PART II: MULTILINGUALISM}

6 On Letting the Brown Bodies Speak (and Write) Nancy Alvarez 83

7 Naneun hangug salam-ibnida: Writing Centers and the MixedRaced Experience

Tammy S. Conard-Salvo 90

Part II: Review 99 
PART III: GENDER AND SEXUALITY

8 Everyday Truths: Reflections from a Woman Writing Center Professional

Anna Sicari 107

9 Of Queers, Jeers, and Fears: Writing Centers as (Im)Possible Safe Spaces

Harry Denny 117

10 The Politics of "I Got It": Intersections, Performances, and Rhetorics of Masculinities in the Center

Robert Mundy 126

Part III: Review $\quad 140$

PART IV: RELIGION

11 On Guard!

Sami Korgan 147

12 Coming Out as Jewish at a Catholic University

Ella Leviyeva 153

13 Floating on Quicksand: Negotiating Academe While Tutoring as a Muslim

Hadi Banat 156

Part IV: Review 173

PART V: CLASS

14 An Adjunct among NYC Teaching Paraprofessionals: Class, Gender, and Race-and What It Means to "Work in Education"

Elizabeth Weaver

179

15 Academic Classism and Writing Center Worker Identity

Liliana M. Naydan 187

16 Other People's Houses: Identity and Service in Writing Center Work

Beth A. Towle 
17 Class Division, Class Affect, and the Role of the Writing Center in Literacy Practices
Anna Rita Napoleone
203

Part V: Review 212

PART VI: (DIS)ABILITY

18 Embracing Learning Differences: Spreading the Word to Writing Centers and Beyond

Tim Zmudka 221

Part VI: Review 237

Conclusion: Identity Politics Redux: A Call for Sustainable Action

Harry Denny, Robert Mundy, Liliana M. Naydan, Richard Sévère, and Anna Sicari $\quad 239$

Afterword

Michele Eodice 246

References 249

About the Contributors

261

Index 263 


\title{
I NTRODUCTION \\ Public Controversies and Identity Politics in Writing Center Theory and Practice
}

\author{
Harry Denny, Robert Mundy, Liliana M. Naydan, \\ Richard Sévère, and Anna Sicari
}

Scan a given week's worth of WCenter listserv messages or attend a writing center staff meeting at any given writing center and you'll see everyday struggles with identity that are faced by the diverse members of our writing center community. How should a writing center director handle a complaint that a tutor is wearing a top another tutor deems as overly provocative? How should a writing center staff respond to a racist cartoon printed in the school newspaper? In what ways might a writing center fashion itself as a safe ( $\mathrm{r}$ ) or brave space-if such a fashioning is even possible-in the face of hate crimes and everyday microaggressions being committed on campus? These questions point to the notion that writing centers involve complicated work that draws attention to the interfacing identities of practitioners and patrons alike-identities Harry Denny (2010) in large part explores in Facing the Center. He argues that diversity underpins writing center work and that writing center practitioners must take up conversations about identity politics in tutor education, fostering dialogue about how difference is negotiated in order to create more socially just spaces. He notes that "identity and the politics of negotiation and face are always present and require inventory and mapping" (28). And he offers his "text as a starting point, launching pad, or intervention in conversations yet to begin" (28).

Certainly, Denny succeeds in starting a line of inquiry in our field. His book is part of a wider conversation that includes books such as Laura Greenfield and Karen Rowan's Writing Centers and the New Racism and Frankie Condon's I Hope I Join the Band, works that focus on the subjects of race and racism (Condon 2012; Greenfield and Rowan 2011b). These texts call for social activism-specifically antiracist work-and they argue for a process of decentering in order for contemporary centers to work toward racial justice via their pedagogies. In our collection, we attempt to 
broaden the focus these and other texts present and continue to complicate how we understand the role identity politics play in writing centers. We aim to explore the very public and yet also personal nature of writing center sessions and of individuals working and collaborating in an environment that necessitates dialogue and negotiation within the self and with others. We put a diverse collection of voices into dialogue with one another about a range of identities including race, gender, class, sexuality, language, ethnicity, positionality, disability, and faith. And we draw attention to the ways in which these identities come to interweave with one another in our writing spaces in the academy. We also look to contemporary public controversies and sociocultural/socioeconomic crises that shape public perceptions of identity. In doing so, we suggest that writing center practitioners must engage in dialogue involving the ways in which tutors, writing center administrators, and writers can most productively and effectively navigate personal or public issues that involve identity. And we suggest that conflict is a means of access that brings to light conversations that have not yet been fully realized in our field. Out in the Center recognizes the writing center exists as a social and cultural creation that extends into the world and not just within the confines of an academic institution. This collection recognizes that moments of crisis, whether they involve public controversies or private meditations, serve as points of entry into an extended dialogue regarding the bodies that enter the writing center space and the subsequent politics that intersect as notions of self are shaped through collaborative work.

\section{WRITING CENTERS BEYOND THE VACUUM}

Writing centers, as Andrea Lunsford (1991) writes in "Collaboration, Control, and the Idea of a Writing Center," fancy themselves as storehouses or resource spaces where writers go for efficient tip sheets for this grammar issue or that genre question; as garrets where writers produce in monastic solitude; or as Burkean parlors where people can talk with and push one another to create knowledge (3-10). Yet each of these notions of the space assumes writers, writing as a product, and the process of writing can be separated out from the social, cultural, economic, and political. They assume writing-its production and its circulation-operates within a vacuum from all that shapes and consumes it. Storehouses, however, are contextual and never provide blanket solutions to every problem; garrets might be illusory; and parlors are never egalitarian or void of the privilege, power, and stakes that pour through the institutions and society that make their existence possible. Writing centers are never 
safe harbors or neutral zones, as if any place like that could exist or has ever existed. They exist as spaces in dynamic interplay with the environments around them. Writing centers are sites where a truism is always in play: the personal is political and the political is personal.

Writing centers are pulsing with activity and conversation, and their walls are permeable, permitting the outside in and the inside out. In other words, in the writing center, the external and the internal have no distinct boundaries, and hence there is no such thing as being only in the center. We are always out in the center, as this collection's title suggests, because the lives of those entering writing centers are never compartmentalized or siloed. The work of becoming and supporting writers is never walled off from the influence of infinite social, cultural, political, and economic currents. Rather, everybody entering a writing center makes public the messy hodgepodges that they are, that they have been, and that they are becoming beyond the moment of their entry. Individuals in a writing center are never distinct from the societal forces that make possible the meaning and legibility of who they are. In turn, writing centers and the campuses on which they are situated can never separate themselves from the communities that surround them.

Certainly, writing centers are agents of institutions that seek to interpolate their subjects to assume their proper positions through education (even when education involves remediation). Institutions that house writing centers seek to reify the boundary between public and private in order to police bodies, identities, and rhetorics. Writing centers depend on a fictive distinction that purports to isolate the everyday intellectual labor of education in disciplinarity, reason, and expression from a world beyond where public and private engage in a never-ending tango. Yet writing centers can and do also function as sites of slippage and subversion where agents can challenge institutionality and where institutions fail to deliver on their objectives. In this sense, all of us who teach and learn in writing centers engage in a certain everyday improvisation, as Beth Boquet (2002) terms it in Noise from the Writing Center, or act as tricksters, as Anne Ellen Geller, Michele Eodice, Frankie Condon, Meg Carroll, and Beth Boquet, the authors of The Everyday Writing Center, describe (Geller et al. 2007). They can and should be spaces in which the tensions of communities can and do manifest. And these tensions become most legible when the tidy operation of tutoring genre, argument, development, sentence clarity, and grammar gets upended by perceptions, preconceived notions, and power dynamics-by compelled disclosure of identity formations such as those that accents or belief systems represent. 
Sometimes tutoring can't happen when personal struggles slip into interactions - or at least it can't happen in textbook ways. Students and staff alike rush to and from class, diving into sessions that can involve first-year writers hashing out their first college essays; upper-level undergraduates orienting themselves to their initial professional group work; graduate students learning to signify as experts; and faculty struggling to overcome time constraints. Yet cutting across these common features and populations in writing centers might also be murkier dynamics: those involving the first-generation college student, the multilingual writer, the learner struggling with intercultural conflict, the biracial tutor, the faculty director who is Other, the graduate student coming out of the closet, or the consultant navigating classes and providing for her child in a single-parent household. The private experiences and internal struggles of these writing center inhabitants are not always visible to passersby, whether passersby are outside administrators or incoming students. Moreover, the intersections that always already define identity are rarely visible to passersby, reinforcing in everyday writing center reality what Jonathan Alexander and David Wallace write with regard to the theoretical work that defines the field of rhetoric and composition: that "little work in our field explores multiple intersections of identity and difference" (Alexander and Wallace 2009, 315-16).

Often, the writing center serves as a space for individuals to come out, to reveal or uncover their identities to relative strangers-consultants or writers who might be working with them to develop ideas for compositions but who in so doing travel down conversational rabbit holes to explore key facets of identity and tensions that accompany them. To appropriate Alexander and Wallace's (2009) words, people in writing centers experience how "a woman may be homophobic, a working-class man may resent the efforts extended to those who are seen as disabled, and a gay man may be prejudiced against those in interracial relationships" (316). Tutors and directors witness (or experience themselves) the struggles of Generation 1.5 writers who feel what Homi K. Bhabha (2004 [1994]) might term as their relative hybridities - the ways in which they are US citizens by nationality but linguistically neither here nor there. Tutors and directors see and may also share the anxieties black men might bring with them when entering spaces following news reports of violence against individuals who look much like them. Instead, writing centers emerge as spaces where features of identity, and intersectionality as it connects those features, make emotionally charged appearances to relative strangers. Writing centers exist as spaces that bolster and challenge identity formation and reify identity by way of conversations that 
always already involve identity-conversations that involve the writer behind the writing and the identity-oriented ideologies that shape any given individual, as well as the language that they produce.

To complement the dynamic social situations that define writing centers, time and again, national crises or media firestorms create flash politics that infiltrate the everyday routine of sessions and staff development within writing centers. While writing, we find ourselves in the midst of many great national tumults - talk of banning Muslims from entering the United States, the injustice of a college student sentenced to only six months imprisonment for the rape of an unconscious woman, or the use of the phrase black-on-black crime to dismiss the Black Lives Matter movement. We read stories of fraternity brothers chanting a racist song that is captured on video and goes viral on the Internet. We see that surveyresearch documents validate women's more-common-than-not experiences with sexual violence. We see images of men and women of color who are dying at the hands of law enforcement. And we see the failure to change law enforcement in the killings of people of color. As a result, we see protests that manifest in response in most major cities make their way into our centers, whether overtly or covertly. Major media report on first-generation students struggling to find connections at elite universities; a coach is fired after being caught using antigay slurs to motivate his athletes; anti-Muslim rhetoric dominates reports of a shooting at a gay nightclub in Orlando: all these infiltrate writing center consultations because they speak to the identities of writing center inhabitants.

Indeed, as we were drafting this project, conversation drifted to a school shooting that had recently taken place at a community college in Oregon. It happened in a writing classroom, and one of us observed that "this kind of thing always happens in a writing space, doesn't it?" The shooter's writing was said to have involved anger and violence, so all of us wondered how a writing instructor or a writing tutor would negotiate the work of a student dealing with anger and rage. We also imagined the challenge of students healing from the trauma of a shooting, whether it be a mass murder or a less publicized everyday act of gun violence. With open-carry laws a reality on more and more campuses, public and private anxiety is legitimately high in the wake of what seems to be a never-ending series of collective traumas, such as those witnessed at the Pulse nightclub in Orlando or senseless random shootings taking place daily in Chicago neighborhoods. These events and the generalized sociocultural anxiety that amplifies them underscore their ubiquity (or at least what we imagine it to be) and the zeitgeist in which writing centers exist. It is not as though writing center staff need permission or 
occasion to discuss and process events such as these. These events are almost hegemonic in their presence in our collective conscience; they feed what people are thinking about and experiencing, and they often drive what professors are assigning for writing and research projects. Writing centers can never be rarified spaces where teaching and learning around writing happens outside a wider (and even micro) social and cultural context. Writing centers must engage the social (and the cultural, political, and economic) because they are part of it.

\section{IDENTITY POLITICS AND THE EDUCATIONAL MISSIONS OF WRITING CENTERS}

Issues of inequitable power that are synonymous with the institution and the larger culture are easily replicated in the center unless we are cognizant of existing power dynamics. Without dialogue, an opportunity to draw parallels between the local and the global, writing centers risk reinforcing division and marginalization and therefore paradoxically working against the educational missions that should be driving them. To prepare for the crises that may emerge in writing sessions, we look to leverage national and global events as teaching moments, occasions Linda Adler-Kassner (2008), Vershawn Ashanti Young (2007, 2011), and Nancy M. Grimm $(1999$, 2006) have identified as organic activism with material consequences. We challenge readers to ask critical questions of these crises in order to learn from them. For instance, what role do we serve in dynamics in which composition classrooms seek to polish students into proper middle-class vernacular and thinking? And how might our experiences and work challenge this agenda and ensure students make informed decisions about how they mark and produce their languages and membership in communities of practice? How might we further imagine ways to position writing centers as subversive spaces that advocate for those who have a marginal status in the academy and who might benefit from the support because of our relative privilege as agents of institutionality? We have no doubt that writing centers speak to the diverse identities of their inhabitants and to identity politics that play out in politically charged spaces.

Like writing centers and those who inhabit them, crises are not selfcontained, nor do they operate independently of a complex social context; they are not confined to the public domain of water-cooler debate. They sustain a pressing relevance, especially for educators who see learning and advocacy as intertwined and who also desire to develop writing center staff education and training that scaffolds from abstract theory 
to enigmatic real-world application. Certainly, many campuses lack the lived experience with diversity and the complexity of identity. Everyday oppression is both material and felt. To echo bell hooks's 1994 Teaching to Transgress, in her chapter "Theory as Liberatory Practice," "When our lived experience of theorizing is fundamentally linked to processes of self-recovery, of collective liberation, no gap exists between theory and practice. Indeed, what such experience makes more evident is the bond between the two" (61). Hence, the personal struggles and negotiations our essays address model the kind of critical dialogue that must happen in tutor education and how we, as writing center inhabitants, must respond to and take on these conversations to promote self-actualization and agency for individuals in order to create spaces of advocacy and social justice in the academy.

What we ask is for our readers to reexamine the work we do and to rethink writing center pedagogy to address the questions we ask in this edited collection: How are we using identity politics as a theoretical framework to address moments of public and personal crisis? How are we teaching people who enter into our spaces about the concept of intersectionality and how to best serve those who seek us out? In a recent Writing Center Journal (WCJ) article, Lori Salem (2016) writes, "I would argue we have nothing to lose and everything to gain from reinventing writing center pedagogy. To be clear, I am not saying that we should look for ways to tinker with or expand our traditional practices. Rather, I am arguing for completely rethinking what we do and why we do it" (164). Salem, in responding to Grimm (2011) and Jackie Grutsch McKinney (2013), calls for writing center practitioners and scholars to respond more directly to the students who enter our spaces and their needs and argues for practices to be more grounded in research. This edited collection takes on Salem's call-we ask readers to not just incorporate this text, or a chapter from this text, into their next tutor training but also to completely rethink the way we understand writing center work in order to best serve the individuals who enter our spaces. How are we understanding collaboration in the writing center and truly using collaborative work to empower individual agency? To echo Grutsch McKinney, this edited collection sees the work in our writing centers extend far beyond one-on-one writing center sessions, and we argue that this book serves as a model for the types of educational work that can occur in the writing center. How are we teaching our tutors to enter into critical dialogue with the individuals with whom they work, as well as with one another? And, more important, how are writing center administrators listening to and learning from their tutors and their private experiences in the writing center? 
While we are addressing the space of the writing center in an institutional context, this edited collection also seeks to challenge more broadly the field of writing center work. At a recent International Writing Centers Association (IWCA) conference, very few panels addressed identity politics in the writing center. Of the few that did, two were fraught with conflict: one panel that addressed identity politics of race, sexuality, and language was packed with a large audience and yet placed in the smallest room the conference offered. People who wanted to attend this session and engage in the educational experience of the discussion were not able to because of the overpacked room. While it is a good sign that people wanted to attend this session, is puzzling, if not telling; what does the organization stand for if it puts such a panel in a small room? Another panel, consisting of a diverse group of undergraduate tutors discussing their bodies in the space of the writing center, went well-a responsive audience filled a room that accommodated all the participants. However, the lack of institutional support this group of tutors received was astonishing. The group of tutors had to rent a car to drive from New York to Pittsburgh, with no funding for accommodations. The five-plus-hour drive made a rather dangerous day trip, allowing the tutors no time to enjoy the conference the way they should. And as Karen Keaton Jackson (2016) points out in her March 7, 2016, post to the WCJ Blog, there is very little institutional or organizational support for historically black colleges and universities (HBCUs) and Hispanicserving institutions (HSIs) to attend regional and national conferences. It must be pointed out that these experiences and conversations all took place in the 2015-2016 academic year, a year in which national conversations about racism, bigotry, xenophobia, and misogyny trickled down into the private and daily experiences of individuals. To what extent do these national conversations inform our everyday thought and practice?

The editors of this collection are very aware of the marginalized voices in the field and the importance of collaboration and support, with all of us working on current research projects that address issues of contingent labor, of systemic issues of sexism and racism, of workingclass identities and their place in the institution and specifically in the writing center. We hope, with this collection of narratives and our focus on critical dialogue in our centers, the field takes up identity politics and addresses everyday real and felt issues of sexism, racism, classism, and homophobia. Through these personal narratives and the essays that follow them, we hope writing center practitioners pay closer attention to how public controversies and concerns inform the everyday private moments that occur in our spaces. We hope the conversation this 
collection constitutes serves as a model for how we, as writing center staff, can have informed, essential conversations that can inform the larger field of composition studies in grassroots ways. If we, as educators and instructors of writing, are not having these conversations with our students, we must ask ourselves, who is? In a climate in which education is being trivialized, with national figures proclaiming a love for the uneducated in an attempt to appear anti-elitist, and with laws passed in states in which anyone can teach in public education, it is vital to make relevant the importance of writing and education to students who enter our spaces. Writing centers must make urgent conversations on the complexity of identity and of oppression in order to create meaningful educational experiences and to promote agency for social justice-not solely in an institutional context but also in a social one.

Who Is Out in the Center? Overviews of Parts and Chapter Summaries

Given the multitude of narratives and theoretical discussions involving identity that have emerged in the field of rhetoric and composition (Alexander 2008; Gilyard 1991; LeCourt 2004, 2006; Matsuda 1999; Miller 1991; Royster and Kirsch 2012; Schell 1997; Villanueva 2003; Young 2007, 2011), only a small percentage gets translated into scholarship for and about writing centers as spaces that involve both public controversies and private struggles and that house students and professionals who understand intersectionality as a lived experience. We are often unprepared to understand, speak, and educate in these moments, moments in which students and staff alike experience private struggles with race, class, gender, sexuality, language, culture, disability, and faith, along with the competing intersections that problematize essential notions of self. Yet each contributor to this collection explores how identities and everyday work around identity politics produce risks and rewards; influence the journeys of teachers/scholars; and make writing centers and the writing programs that at times house them or exist in dynamic interplay with them into transformative arenas for ongoing dialogue. Such a conversation, one with many invested parties, begs for contributions from across the spectrum of practitioners. The voices of students, tutors, writing center and program directors, and composition instructors, both on and off the tenure track, that make up our collection speak with attention to intersectionality about their varied experiences.

In part 1, we explore questions involving race through essays authored by a current graduate student tutor, two former tutors, and a former writing center director. Talisha Haltiwanger Morrison writes 
about the embodiment of race in the writing center, her search for community at predominantly white institutions, and the everyday microaggressions and flat-out racism she confronts as a black woman tutoring and teaching writing. Alexandria Lockett reflects on her work with a variety of students at her graduate institution, noting that black bodies are under constant scrutiny and suspicion in writing centers, just as they are in any other social space. To contest that dynamic, Lockett worked to challenge that surveillance by actively participating in how her sessions were documented and reported and by changing protocols to ensure all tutors' experiences were captured in narratives. Richard Sévère further extends this discussion of bodies and race, drawing on writing center scholarship and critical theory to address how his physicality as a black man affects perceptions and dynamics in writing centers. Allia Abdullah-Matta bridges experiences with race in the classroom to those in the writing center and theorizes that there are connections between bodies and the politics of race. Rochell Isaac makes connections among the students with whom she has worked, their struggles to think critically about writing tasks, and their deeper ambivalence and reluctance, even resistance, to share their experiences in an academic arena predicated on judgement and evaluation of experiences. Isaac argues that education, as a liberatory practice, and the constellation of pedagogies that translate it into action place working-class African American students in paradoxical learning spaces, trying to assimilate standards while maintaining access to a lived reality of their own.

In part 2 of this collection, we further extend the critical race conversation begun in part 1. Nancy Alvarez's essay takes up the lessons of tutoring in Spanish at a community college in the Bronx and her transition to tutoring in an English de facto environment, ironically in one of the most linguistically diverse urban areas in the world. The whiteness of the seemingly English-only writing center at her graduate institution caused her deep conflict, and she pushed that writing center to begin to think about the demographics of its staffing and clients, as well as how it put multilingual policies into practice. Tammy S. Conard-Salvo further deepens this intersectionality of race and linguistics by addressing how she has navigated being a multilingual administrator by learning to embrace but also to be wary of the ability to code switch in sessions.

Part 3 begins a subtle movement from identity as more or less embodied to discussions of gender and sexuality that force tutors and administrators alike to disclose identities with clients and staff. Anna Sicari writes about navigating her identity as a junior writing center professional, all the while confronting institutional and societal sexism, whether in the 
form of peer administrators challenging her place in and knowledge of the field or in the shape of gendered dynamics with male colleagues. Sicari turns to feminist theory both to light a path forward for writing center professionals and to underscore the material reality generations of women academics and their peers directing writing centers have experienced. Harry Denny reflects on instances of harassment, pointing to the conflicting pressures for LGBTQ+ writing center tutors and professionals to be out, to disclose their identities, or to be visible figures and leaders, all the while underscoring the risk and threat of being out. He recognizes the implicit privilege of having the ability to choose to be out when some have bodies and performativities that signify them in advance of speaking, particularly people of color. Robert Mundy takes up the tensions inherent to masculinity in the context of seeking help, help with anything, and the result of making oneself vulnerable and in need of support in a culture that stigmatizes men seeking and providing nurturance to one another. Mundy addresses how a certain sort of machismo makes possible giving support without undermining a certain "guy's code" of masculinity.

Just as our public genders and sexualities can mask private struggles to negotiate the everyday reality of tutoring sessions, a person's spirituality is not always carried on their sleeve or hung around their neck. And, of course, clients, tutors, and administrators more often than not come from religious traditions that inform how they think, how they express themselves, and, more broadly, who they are. Yet our literature in writing centers provides little guidance or opportunity for writing center training on the topic. In part 4, Sami Korgan writes in her piece about navigating writing center sessions and breakroom conversations about religion at a religious institution where her faith is in the minority. Much like the other people in this collection who reflect on coming out in sessions and to peers, Korgan also speaks to how she addresses the pressure to confess her identity and theology. Like Korgan, Ella Leviyeva reflects on being another religious minority, Jewish, at the same institution and on facing the pressure to be a spokesperson for her faith as well as contesting the assumptions of the majority religion among her peers and clients in the writing center. Hadi Banat shares the complexities of being Muslim and multilingual at a predominantly white institution and how it plays out in everyday interactions in a writing center context. He details occasions in which clients and peers ask him to speak on behalf of his faith in a wider social and political environment that is generally hostile and uneducated about the diversity of theologies in Islam.

Parts 5 and 6 advance discussions of tutor experiences with economic class and disability in sessions. Both these foci document additional 
aspects of identity that are ubiquitous (yet often invisible) and that tutors and clients bring to sessions and struggle to disclose. Tutor-education texts rarely push readers to imagine how classed identity impacts one-toone learning. Elizabeth Weaver writes about being a professional contingent academic worker, moving around New York City for gigs as a tutor and an adjunct instructor. She connects these working conditions to her roots as a working-class, first-generation student from the Midwest who earned a graduate degree from an Ivy League institution. Like Weaver, Liliana M. Naydan speaks to the experiences of contingent writing center work in graduate school, of the dynamics of labor contingency within universities, and of the need for graduate tutors to unionize. Beth A. Towle addresses moments when class is foregrounded in sessions and therefore makes her contend with her own negotiation of class through education and the need to come out as working class, frequently to her clients' disappointment, as they seem to wish for expert insight from those who possess inherent privilege. Anna Rita Napoleone complicates notions of privilege by exploring times in which her standing was checked by her working-class affect and/or register, leaving her frustrated by the limited options available to her as a student and professional. Although she is compelled to challenge the labels assigned to her as an immigrant and member of the working class, she echoes the sentiment and frustration others have expressed: how long can one fight this fight and how possible is success given the rigidity of higher education? Following these tutors' and directors' discussions of class identity, Tim Zmudka offers insight on the experience of being learning disabled in a writing center. While many disabilities are embodied, Zmudka writes about himself and the difficult negotiation learning disabled tutors must undertake. He notes that having attention deficit hyperactivity disorder (ADHD), even though it is always present in education and writing centers, carries great stigma in society and culture, which makes disclosing this aspect of who he is precarious for his credibility in sessions but crucial for building awareness of its presence in education and writing centers.

We wrap up the collection with a concluding chapter that brings together the lessons from all our contributors. This collaborative essay calls for sustainable action and research in writing centers, encouraging tutors and directors to imagine local ways in which they can call attention to identity, document its impact through inquiry, and shape policy both within and beyond the center and their institutions. While we each know and have experienced the marginality of writing centers in a host of ways, we argue that writing center practitioners have an obligation to move leadership in ways that makes sense in their contexts, to continue 
to foster change and inclusiveness in institutions that intrinsically tend toward the status quo instead of challenging it.

\section{A Reader's Guide to Our Collection}

Any attempt at addressing the complexities of identity in writing centers is a tall order, and some might wonder why we structure the book the way we do, or why a part on race precedes those on other aspects of identity. Others might wonder whether our authors could have complicated their identities a bit more, recognizing nobody ever occupies a position of complete marginality or of absolute domination. We do not intend the structure to represent some sort of parable of oppression Olympics ordered from most to least. As editors, we recognize, along with our authors, the privilege and complexity from which we express our reflections. We know that as tutors, directors, faculty, and administrators we always already inhabit some degree of interiority to the tactics and relations of power and status in the academy writ large but also on the everyday level of how our local units operate and the missions that guide them. We also began this project thinking about the absence of theory in so many of the texts in our profession that have taken up identity politics, however well intended, and about the underexplored range of experiences and the authenticity of the multiple ways in which diversity and oppression play out, particularly for bodies that aren't white, male, middle class, straight, Christian, or able bodied. We are also aware, with few exceptions, that our current texts have rarely foregrounded the actual voices of real tutors who have experienced the very phenomena our classic texts channel obliquely but without, for want of a better term, street cred. We enter this dialogue fully recognizing that capturing every voice and every perspective would be a fool's errand, a folly of political correctness. Instead, we ask readers to riff on our authors' narratives and our responses through their own experiences. We also hope readers will find spaces and opportunities to extend the conversations we begin, as we don't intend this collection to shut down or offer a supposed last word on the dynamics and insights we offer across these pages.

Pragmatically, we had to make decisions about the order of the authors' essays and decided to structure the collection along an index of the intensity of the politics of identity, both historically and in relation to our present sociocultural moment. Quite simply, race, and especially the experiences of African Americans, occupies a powerful center in the United States and academia that just cannot be denied; it, of course, does not diminish the power and felt experience of the innumerable 
other aspects of who we are as humans, citizens, educators, students, and leaders. Our colleagues who authored the Everyday Writing Center capture the crux of our values and thinking so well:

A common objection to studying and working against racism specifically is that there are other forms of oppression, such as sexism, classism, and homophobia for which critical race theory and anti-racism do not account. While we acknowledge the importance of working for justice in these other crucial areas, we offer anti-racism work as a place to begin for what we believe to be compelling reasons: Racism cuts through multiple identities and magnifies the effects and impact of other manifestations of oppression. The experience of people of color who are also women, working class, and/or gay is markedly different from the experiences of whites who share those other identities. (Geller et al. 2007, 91-92)

As a result of the wise insights of our reviewers and Michael Spooner, our intrepid editor, we go further, we think, than Geller et al. and other collections that take up race. We revised our manuscript with a specific mission to foreground the complexity and intersectionality of identity. No other current text has such a self-awareness and an antifoundationalist mission; we pushed our contributors to revise with a sense of how their narratives might refuse to stop with just another contribution to the ever-expanding lore, or what Grutsch McKinney terms the "grand narratives" on which writing center scholarship tends to depend (too much, some might argue). Readers will notice that the complexity and nuance that comes with perspective and age, as a tutor graduates to other professional experiences or as a tutor (or director) recognizes that their unique privilege in a situation is different from those who occupy other positions. Following part 1 , on race, we turn to a discussion of multilingualism. The politics of language commingles in our society with the politics of race; in practice, they cannot be separated because the bodies and the voices whose accented English or vernaculars are policed are easily racialized bodies, albeit often different from the bodies involved in the centuries-long struggle against racial oppression and white supremacy as exercised in the United States.

Just like race and the politics of language, gender and sexual identities are ubiquitous in the landscapes of writing centers. The fluidity and fear of transgressing conventions makes the recognition and performance of gender and sex more charged today than ever before. That tension and its heat lead us to share the perspectives of our authors, who push at the boundaries and implications of gender and sexuality in the everyday work of writing centers. Everyone who enters our spaces embodies and performs gender and sexuality as part of the amalgam of 
who they are, and those practices are rife with both personal and institutional complexity. Like all spaces, writing centers function within patriarchy; however, confronting our gendered/sexual selves is amplified by the intimacy of writing and by the conferences in which it is discussed. That work happening in writing centers operates from pedagogical principles that value the feminist influences of collaborative learning and collective support and encouragement. The very movement that made possible the mantra "the personal is political" also fostered teaching moments that encourage individual, deep connection to the writing process. The insights the feminist movement made possible for challenging the wider dynamics and relations of sex and gender also contributed to a questioning of sexuality, another intrinsic component to who we are and how we identify. Queering our sexual politics isn't just the stuff of protest surrounding antidiscrimination and equal treatment under the law. The assumptions and hegemony of sexuality are ever present in sessions and tutor education, just as whiteness and patriarchy are.

We conclude by turning to parts on faith, class, and disability, all of which are less visible aspects of identity but no less critical to who we are and what influences how we perform our sense of self. Each of these elements of our identities requires a performance, if not an explicit disclosure, in interactions, particularly in sessions. We grant that any of these features of identity might be legible, as race, ethnicity, gender, and sexuality are, but they require a certain literacy for recognition that is different from the literacy required for recognition of those other components of identity. We also readily concede that in coming out, in disclosing their class, faith, or disability, individuals can be the objects of prejudice, stereotypes, bigotry, and even discrimination. All these effects of oppression, whoever the object, are always deplorable and immoral, by our view. We cluster these subjects in the latter part of the text not to minimize or marginalize them but out of pure recognition that their histories and frequency are far less intense or charged in US society and education.

We do, however, caution our readers to avoid using identity politics as a tactic to leverage over other groups, to jockey for status, or to privilege one performativity over another. Although the collection is organized by aspects of who we are as consultants, directors, and those in between, we are fully aware that seeing these components of who we are as totalizing and galvanizing, even stable, presents its own unique set of concerns, namely the inability to fully espouse a perspective that embodies intersectionality. At the same time, we realize how difficult perspective can be, particularly when contemplating and reacting to moments that may have elicited fear, pain, or frustration. With great ease, we can invoke a 
rhetoric that essentializes experience, and in doing so, we risk keeping others from engaging with us-holding them to a hard line of who can and should identify accordingly. Instead, we ask readers to find and build alliances on the nuance of experience. We encourage readers to discover our gaps or lapses and to imagine how they might individually, or in collaboration, further complicate and extend the conversation with others and through others. We invite readers to talk with one another and with all the writers in this collection, to praise, to challenge, to speculate, to deepen, and to build toward further inquiry. 